\title{
APRENDIZADO DE MEDICINA NOS SERVIÇOS DE ATENÇÃO PRIMÁRIA E NO CONTATO COM A COMUNIDADE
}

\author{
MEDICAL APPRENTICESHIP IN PRIMARY HEALTH CARE COMMUNITY SERVICES
}

Roberto Teixeira Mendes; Paulo Eduardo Moreira Rodrigues da Silva \& Maria Aparecida Affonso Moysés

Docentes do Departamento de Pediatria da Faculdade de Ciências Médicas da UNICAMP.

Correspondência: Prof.Dr. Paulo Eduardo Moreira Rodrigues da Silva. Departamento de Pediatria - FCM - UNICAMP. Rua Alexander Fleming, 181 - Caixa Postal, 6111 - Distrito Barão Geraldo - CEP: 13083- 970 - Campinas - SP - Fone: 019-2397866/2397096 FAX: 019-2393114 e-mail: FCMADM@turing.unicamp.br

MENDES RT; SILVA PEMR da \& MOYSÉS MAA. Aprendizado de medicina nos serviços de atenção primária e no contato com a comunidade. Medicina, Ribeirão Preto, 29: 420-428, out./dez. 1996.

RESUMO: Recuperando a relação histórica entre ensino médico e estruturas de assistência e pesquisa fora do ambiente universitário, os autores apresentam uma concepção de ensino, na Rede de Saúde, que, dialogando com os projetos de Reforma do Ensino Médico mais importantes e conhecidos, subsidia uma crítica aos objetivos e finalidades desses projetos. Ao mesmo tempo, recuperam a possibilidade de, a partir do desenvolvimento da prática clínica no âmbito dos Centros de Saúde da Rede Básica do Município de Campinas, ampliar a visão dos alunos de Medicina sobre os problemas de saúde que afetam as crianças e a especificidade do trabalho médico nesses serviços. A prática clínica nos Centros de Saúde, o ensino e as pesquisas aí desenvolvidas têm por base a noção de que a saúde e a doença são situações sentidas e vividas por indivíduos em sociedade, sem abrir mão das abordagens derivadas da Epidemiologia e das Ciências Sociais, assim como do conhecimento elaborado pela clínica anátomofisiopatológica. A reflexão possível, a partir desta alternativa de ensino e pesquisa, é a de que existem outras possibilidades de inserção do ensino na Rede Básica, não contempladas pelos movimentos de Reforma do Ensino Médico.

UNITERMos: Cuidados Primários de Saúde. Educação Médica. Pediatria.

O ensino médico realizado no âmbito dos Serviços de Atenção Primária não traz em si qualquer especificidade pedagógica, tecnológica ou científica, de modo que essa atividade, constante dos cursos de graduação e eventualmente obrigatória, não traz, a priori, qualquer relevância, no sentido de contribuir na formação médica, a não ser permitir o contato inicial dos alunos com as unidades de serviços médico-sanitários, que, por sua vez, são muito diferentes entre si, ainda que em um mesmo município. As diferentes modalidades de inserção do ensino médico nessas unidades não se constituem tampouco em novidades no âmbito da formação médica, uma vez que muitas especialidades constituíram parte de seus campos de saberes e práticas em serviços de primeira linha, como os Dispensários para Crianças, os Serviços de Puericultura, as unidades de Higiene e Saúde Pública, os Dispensários da Lepra, da Tuberculose, do Tracoma e por aí a fora, situando-nos, apenas no Brasil, na primeira metade do século.

A formação médica, desde o advento da Medicina Científica de Base Clínica (a clínica anátomopatológica experimental) do século XIX, tem sempre exigido um rol de atividades fora do espaço das Faculdades de Medicina e das Universidades. Sem querer estabelecer um raciocínio linear, é evidente que, independente do desenvolvimento científico-tecnológico das Faculdades de Medicina, e da modernização das con- 
cepções e técnicas didático-pedagógicas, é impossível, para cada uma delas, manter sob sua jurisdição atividades correspondentes a todas as modalidades possíveis de prática médica, com o intuito de oferecêlas para a formação médica geral ou especializada. Nesse sentido, a clínica anátomopatológica de Boerhaave, em meados do século XVII, inaugura o processo de questionamento concreto da formação acadêmica exclusiva das faculdades, seguida, mais tarde, pelos laboratórios de fisiologia/bioquímica, os institutos de pesquisa bacteriológica/imunológica, enfim, por todas as atividades científicas nucleares do saber médico moderno. No plano da aplicação dos saberes, as clínicas hospitalares e ambulatoriais constituíram-se na contramão dos ambientes de trabalho onde se instalaram, e as policlínicas, gerais e especializadas, rearranjaram os serviços também de modo a propiciar o ensino e a pesquisa. Institutos de pesquisa, clínicas hospitalares e ambulatoriais, policlínicas, serviços de higiene, puericultura, materno-infantis, todos serviram para a formação médica científica e tecnológica "por fora" do ambiente acadêmico.

Para o advento do ensino médico de base científica, condensado em sua concepção idealizada, no início deste século, pelo relatório Flexner ${ }^{1}$, foi necessária a incorporação de todas essas estruturas de trabalho, pesquisa e ensino, às Faculdades de Medicina, conformando o Hospital Universitário moderno, embora, ainda assim, laboratórios, clínicas e ambulatórios possam não estar situados em um mesmo espaço. O ensino da Medicina Científica vai ser centrado na aquisição progressiva de conhecimentos fundamentais, das ciências básicas (Anatomia, Fisiologia, Bioquímica, etc) que constituirão o Ciclo Básico, até o Ciclo Clínico, quando deverão ser integradas ao saber e prática das clínicas.

Ao mesmo tempo, o estudante é iniciado no método científico-experimental, de modo que o profissional assim formado tenha a competência necessária, tanto para a atividade assistencial, típica da profissão, como para a elaboração do saber que a fundamenta, o que permitiria uma prática de base científica e não apenas técnica, um saber-fazer sempre reatualizado pelo avanço da Ciência, um saber-fazer sempre transformado pela experiência individual: ciência e arte de curar.

A crítica à formação médica, até o século passado, voltava-se contra o "saber filosófico" transmitido pela academia, à prática puramente empírica e à falta de cientificidade de ambos. Com o advento da
Medicina Científica e Tecnológica, ensinada e praticada pelas faculdades e hospitais universitários, a crítica volta-se, principalmente, para a especialização excessiva e precoce, entendida como resultado do recorte progressivo do conhecimento operado pelo modo de produção do saber científico.

A parcialização do saber que toma o ser humano como objeto de investigação com vistas a conhecer suas estruturas e funções biológicas, as relações destas com o ambiente, com as condições de vida, os agentes patogênicos, ao se tornar a base de formação do médico, levaria a uma desconexão progressiva da "totalidade biopsico-sócio-cultural" do indivíduo submetido à prática médica.

A almejada cientificidade da pesquisa, do ensino e da prática médica estaria gerando, segundo essa visão crítica, uma excessiva biologização do conhecimento, estabelecendo, em um primeiro plano, a ruptura do organismo com as outras dimensões concretas da existência humana e, no próprio plano biológico, uma formulação restrita e estanque de objetos parcelares do trabalho médico, consubstanciada nas especialidades médicas. Desse modo, perde-se a totalidade individual como objeto da preocupação médica, ao mesmo tempo em que a unidade de produção típicaideal de trabalho médico, a consulta, é desmembrada em uma série de atos parciais, diagnósticos e terapêuticos, realizados por diferentes especialistas (às vezes, apenas controlados por médicos, mas realizados por outros profissionais), em uma dinâmica que não chega nunca a alcançar a recomposição dos atos médicos parcelares.

Com base nessa concepção crítica do movimento de especialização médica, desde a formação, surgem os movimentos de reforma médica, visando reintegrar o conhecimento no âmbito da formação para alcançar a recomposição do ato médico na prática profissional: Medicina Integral, Médico de Família, Médico Generalista, etc.

Transcendendo esse movimento, e tendo como objetivo a extensão da cobertura às populações desprovidas de acesso à assistência médica, ofertada via mercado ou via sistema previdenciário, surge o movimento pela Medicina Comunitária, que lança mão da possibilidade de organizar serviços com base em uma "comunidade", termo que não chega a ser precisado com clareza, de modo que, de imediato, a noção de comunidade fica impregnada da condição de pobreza e carência, própria das populações a que se destina. Entretanto, ao revigorar o sentido globalizante da Medi- 
cina Integral, e ao acoplá-lo ao sentido de projeto político de organização de comunidades que, de fato, ainda não existiam, a Medicina Comunitária empolga parte da Academia e das Instituições de Saúde Pública (Ministério e Secretarias Estaduais e Municipais de Saúde). Empolgam-se, também, os agentes sociais envolvidos com a transformação da prática médica inserida em uma nova estrutura social: essa prática, modificada, constituir-se-ia dialeticamente em praxis transformadora/produto da transformação. Concebe-se, assim, a educação médica também como produto/instrumento de mudança da prática médica, em um movimento de ampliação da autonomia das práticas com relação à estrutura social e aos seus determinantes.

Por outro lado, dado o custo envolvido com a extensão da cobertura assistencial, se feita nos moldes do modelo tecnológico dominante, propõe-se uma simplificação (ou adequação) da tecnologia, justificada pela morbidade presente na população a ser atendida, de modo que a parcialização da consulta médica pela via da delegação de funções é tida como desejável, pois, aparentemente, ocorre no sentido inverso da especialização médica. Busca-se, com a simplificação tecnológica e a delegação de funções, reduzir o custo e aumentar o rendimento do trabalho médico, o que, é evidente, supõe um médico adequadamente formado para integrar o processo de trabalho assim constituído.

Além disso, esse movimento de reforma médica amplia o escopo da transformação da educação médica, ao propor também uma redução da "distância" que o hospital universitário mantém da "casuística geral", por selecionar casos de acordo com o interesse científico. Propõe-se a imersão do complexo hospitalar universitário na rede assistencial, ainda que conservando a função de retaguarda complexa.

A mudança do perfil assistencial dos hospitais universitários não é a causa principal da perda de seu caráter de hospital de clínicas, entendido aqui em sua concepção original de hospital em que os serviços se constituem de modo a permitir o ensino e a pesquisa sobre casos selecionados. Ocorre que a seleção de casos está contida pelas demandas de serviços externos, ou mesmo espontânea, de forma que o controle sobre a casuística, por parte das clínicas, diminuiu, mas não desapareceu. Entretanto, nos hospitais universitários, o modo de incorporação da tecnologia à assistência tem se pautado mais pela lógica dos serviços médicos, em geral, em um movimento correlato ao aumento indiscriminado da demanda. Sem ter um referencial próprio sobre a incorporação de tecnologia, no âmbito do ensino e da pesquisa, o hospital universitário hoje em dia reproduz, com bastante fidelidade, o movimento geral de consumo dos bens e produtos da indústria de equipamentos e farmacêutica. Desse modo, o ensino é impregnado pela tecnologia, mas não pela ciência e pelo saber que, por anterioridade, permitem e exigem a conformação daquela tecnologia.

Também os hospitais universitários deixaram de ser "de clínicas" no sentido original, de desenvolver clínicas, pois as reuniões de casos e a discussão caso a caso, a comparação da casuística com a bibliografia, a produção de trabalhos sobre a casuística, têm sido substituídas pela ênfase no atendimento puro e simples, ainda que de boa qualidade. A ciência, na verdade, parece estar "ao fundo" das atividades assistenciais, mas não inserida nelas, a não ser pela tecnologia material aplicada.

Com relação às práticas de saúde, médicas ou não, deslocadas da medicina científica e tecnológica, o preconceito, o desconhecimento, a opinião superficial não contribuem para a sustentação da medicina ensinada nas faculdades frente às outras práticas. Em sendo, todas, práticas sociais, a relação entre elas não se dá exclusivamente no campo do saber e do ensino, mas principalmente na resposta que cada uma representa a demandas socialmente constituídas. Entender isso é fundamental para os docentes, pois aí também está contida uma crítica concreta (ainda que não formulada cientificamente) à capacidade da medicina científico-tecnológica de responder à totalidade das demandas relacionadas à saúde, promessa que sempre sustentou, mas nunca cumpriu.

Por último, tendo em vista a discussão específica sobre a inserção do ensino médico no âmbito dos Serviços de Atenção Primária à Saúde (APS), e saindo das questões levantadas como preliminares a essa discussão, queremos afirmar dois pontos de vista que norteiam nossa prática. Com relação à possibilidade de impactar a futura prática dos médicos, pensamos que as relações entre ensino e trabalho médico, entre faculdade de Medicina (incluindo o hospital) e mercado (de trabalho médico e de insumos para esse mercado) deve ser explicitada para que se torne objeto do debate acadêmico, dos docentes e dos alunos. A inserção do ensino na Rede de Saúde Pública constitui espaço fundamental para elevar essa relação ao plano da reflexão, antes que da prescrição. A prática futura estaria, então, impactada, não por um modelo de comportamento adequado a esta ou aquela modalidade de serviço nesta ou naquela conjuntura, mas por 
uma consciência da relação que o trabalho estabelece com a estrutura social.

Por referência à formação científica do médico, queremos deixar claro que a Ciência, modo de produzir conhecimento sobre a realidade, em suas diversas modalidades, constitui, para nós, a base da reflexão médica sobre os problemas de saúde e sua determinação, social, e não apenas base de compreensão dos fenômenos biológicos e via de incorporação da tecnologia material, na prática médica. Neste sentido, aproveitamos a elaboração de $\mathrm{Kosik}^{2}$ sobre a relação ciência - totalidade concreta: "A diferenciação da ciência - que em certas etapas da evolução parecia ameaçar a unidade e apresentava o perigo de dividir o mundo, a natureza, a matéria em todos independentes e isolados, e de transformar os cientistas dedicados às disciplinas isoladas em eremitas solitários (...) - leva, ao contrário, com seus efetivos resultados e conseqüencias, a sempre mais profundo descobrimento e a maior conhecimento da unidade do real. De outro lado, esta compreensão mais profunda da unidade do real representa uma compreensão também mais profunda da especificidade de cada campo do real e de cada fenômeno. Em pleno contraste com o romântico desprezo pelas ciências naturais e pela técnica, foram, justamente, a moderna técnica, a Cibernética, a Física e a Biologia que abriram novos caminhos ao desenvolvimento do Humanismo e à investigação daquilo que é especificamente humano". (p.37)

\section{O ENSINO MÉDICO INSERIDO NA REDE BÁSICA DE SAÚDE}

Saindo das considerações sobre os movimentos de reforma do ensino e da prática médica, mas sem perdê-los de vista, assim como as afirmações feitas sobre a amplitude e a profundidade possíveis de qualquer proposta de mudança do ensino médico, seremos mais pragmáticos na apresentação de nossa concepção de ensino vinculado à Atenção Primária à Saúde e à Comunidade.

Em primeiro lugar, entendemos que o conceito "Atenção Primária à Saúde" é um conceito instrumental, que se vale de toda a experiência acumulada no planejamento e execução de serviços públicos de primeira linha. Possui uma lógica de priorização de ações, baseada em critérios de risco, magnitude, vulnerabilidade, viabilidade, eficácia e eficiência. Lança mão de tecnologias consagradas por esses critérios e a programação de ações, a padronização de condutas, a avaliação constante da cobertura das ações e dos impactos sobre os índices de saúde da população coberta são parte integrante dos projetos de Atenção Primária. Ocorre que a Rede Básica de Saúde, entendida como os serviços ofertados via Centros de Saúde, Ambulatórios de Primeira Linha e Serviços de Pronto Atendimento, já ultrapassaram, em muito, o modelo organizacional da Atenção Primária, pois representam hoje uma ampliação da capacidade de atendimento médico instalada na Rede Pública, por relação com o período em que a Atenção Primária surge como proposta médico-sanitária.

Entretanto, vários dos conteúdos das propostas de Atenção Primária foram abandonados sem nunca terem sido efetivados com toda a radicalidade. O padrão assistencial da Rede Básica de Saúde dos grandes municípios, concebido como modelos tecnoassistenciais ou tecnooperacionais, mesclam atualmente, em variadas proporções e combinações, o atendimento médico propriamente dito, com as atividades precípuas da estrutura médico-sanitária: vacinação, pré-natal, vigilância nutricional, vigilância epidemiológica, atividade de grupo, etc. Como já dito anteriormente, essa variabilidade de modelos convive em um mesmo município, transgredindo, na prática, as formulações mais doutrinárias e homogeneizantes, produzidas pelas Secretarias Municipais de Saúde. Não vamos discutir aqui as razões mais profundas dessa variabilidade, mas constatá-la é o primeiro passo para elaborar um projeto de inserção do ensino nessa realidade.

Em segundo lugar, a opção de trabalhar em Centros de Saúde, dada a precariedade de que se reveste a Rede Básica, em geral, não está no primeiro plano da escala valorativa de trabalhos médicos. No entanto, talvez a maior parte dos médicos formados nos últimos cinco anos tenham trabalhado na Rede Básica, em seu primeiro emprego, mesmo após a especialização. Na conjuntura atual, apontar a Rede Básica (e o Serviço Público) como o maior mercado de trabalho médico, não passa de mera constatação, que, entretanto, é lamentada por boa parte da Academia, inclusive os alunos.

Em terceiro lugar, tomando já o trabalho médico realizado na Rede Básica como objeto de preocupação, pode-se constatar que:

1- as consultas praticamente limitam-se à queixa-conduta, com pouquíssimo empenho do médico, em elevar o padrão clínico de sua consulta; 
2- a demanda é fortemente reprimida, sendo que qualquer tentativa de organizá-la, no sentido de diminuir a repressão e permitir um trabalho mais adequado à própria finalidade do serviço, sofre sérias resistências por parte de toda a equipe, pois a lógica do bem atender está sempre submetida a interesses particulares da equipe, que se protege atrás de normas e procedimentos técnicos do próprio serviço;

3- o progressivo direcionamento da demanda dos PAMS, pronto-socorros e ambulatórios conveniados e contratados do antigo INPS, desde as AIS, em meados dos anos 80, jogou para a Rede Básica a chamada "porta de entrada", sem que se criassem as "portas de saída", de modo que essa demanda fica represada nos C.S. e PAMs municipais, reforçando seu caráter de atendimento eventual e descontínuo;

4- essa transferência de demanda acabou por deslocar a antiga clientela dos C.S., os "não previdenciários", exatamente os que mais se beneficiariam do atendimento programático e do seguimento rotineiro.

Por último, sendo os Centros de Saúde as unidades nas quais, (de acordo com todas as propostas e projetos que lhe atribuam destaque), a maior parte dos "casos mais simples e de menor complexidade" serão resolvidos, ele aparece também como unidade desprovida de tecnologia, o que de certa forma reforça e autoriza o pronto-atendimento com base na queixaconduta, e o encaminhamento imediato dos "casos complexos", além dos de maior gravidade e urgência.

Como inserir então o ensino nessa rede de serviços precária e mal formulada? Qual o papel reservado para essas unidades nos próximos rearranjos dos serviços médico-sanitários? Como formular um projeto de ensino sem garantias de continuidade do modelo assistencial posto para o momento? Aparentemente, toda essa caracterização dos movimentos de reforma e da Rede Básica é paralisante, e a primeira idéia que vem à mente é a de se montar um serviço-modelo, onde os problemas sejam superados pelo controle da Academia e pelo investimento via convênios ou outros. Essa é a idéia básica dos Centros de Saúde-Escola, atualmente ampliada pela concepção de Distritos Sanitários Docente-Assistenciais. Baseados em nossa experiência, pensamos que os Centros de Saúde-Escola e os Distritos Sanitários Docente-Assistenciais, embora se configurem em alternativas razoáveis para a experimentação de alternativas organizacionais, no campo da gestão, planejamento, hierarquização, desenvolvimento de ações de vigilância, alternativas programáticas, padronização de condutas, não conseguem superar exatamente o estigma de serem idealizados, ficando sempre entre a alternativa do confronto com os modelos vigentes (confronto positivo, mas ainda assim confronto) e a dificuldade de priorizar o ensino. Distanciam-se, em geral, das alternativas possíveis de enfrentamento da realidade assistencial dos serviços públicos e da implementação de atividade de ensino que transcendam o efeito-demonstração.

Nossa concepção é de que o ensino seja inserido nos serviços existentes e nos Distritos Sanitários (se existirem) já conformados pelas Secretarias Municipais de Saúde. Retomamos, desse modo, a capacidade de crítica, por dentro, dos serviços municipais, e não por fora, como "luz a ser seguida", o que, pela própria relação que a Academia estabelece com os serviços públicos em geral, já é fonte de resistência ao debate aberto e franco. A inserção do ensino na Rede Básica significa compartilhar as decisões como membro da equipe de trabalho, função esta que deve ser claramente delegada a um docente que atue cotidianamente no serviço, de modo que este não tenha que constantemente "discutir com seus pares" alternativas que se apresentem ao trabalho.

O Centro de Saúde, não se constituindo em panacéia para a integração do currículo, dos saberes, das profundidades perdidas, da casuística diferenciada do hospital, pode, no entanto, fornecer um campo de atuação que amplie a experiência do aluno, vivida durante a graduação, ou do residente de algumas áreas. A nosso ver, a contribuição mais importante, não a única, é, exatamente, a possibilidade de o aluno desenvolver uma maior capacidade de percepção dos limites da tecnologia material e da importância da tecnologia não-material na abordagem médica dos problemas de saúde.

O ensino-médico, por estar centrado na clínica, dispõe em torno dela os outros elementos que dão base ao raciocínio clínico ou que dele derivam. O aluno de Medicina, tendo sua formação moldada pelo raciocínio clínico, em geral, se apropria de outros conhecimentos, submetendo-os ao crivo do olhar clínico. Daí, pretendendo-se que ele se aproxime de outras dimensões da problemática de saúde, individual e coletiva, um caminho, que nos parece adequado à realidade do ensino médico atual, é exatamente o que tem a experiência clínica como ponto de partida. Neste aspecto, a abordagem de um paciente nos Centros de Saúde deveria guardar grandes diferenças com relação à abor- 
dagem do paciente em ambulatório especializado hospitalar, de um paciente internado, ou de um paciente que acorre ao Pronto-Socorro. Uma boa parte das queixas apresentadas ao clínico do Centro de Saúde vem envolvida com situações referentes à família e à moradia, ao acesso a bens de consumo, lazer, atividade física, relações de trabalho, ambiente de trabalho, etc...

Ou seja, se, ao adentrar o hospital, o paciente tem seus laços sócio-afetivos rompidos, isso se dá, em boa medida, porque o hospital existe em função do tipo de manipulação a que vai submeter o paciente e esta é de base anatomofisiopatológica, realmente biologizante. Com isso, não queremos justificar o padrão de distanciamento que se estabelece entre o médico e o paciente no ambiente hospitalar, mas apontar para uma característica intrínseca à prática hospitalar. Não faz muita diferença, do ponto de vista da eficácia da intervenção, conhecer detalhes da vida de um paciente que vai para uma cirurgia, para uma UTI ou, mesmo, daquele que chega acidentado ao Pronto-Socorro.

Por outro lado, ao ter sua formação clínica desenvolvida no ambiente hospitalar, o aluno aprende a trabalhar com os limites de atribuições estabelecidas para o trabalho médico-hospitalar, definidos pela forma como se organiza o trabalho médico no hospital, as finalidades postas para esse trabalho, os meios de trabalho, o modo de conceber o objeto de trabalho. O que foge à lesão e à disfunção orgânica detectável e tratável, é "encaminhado" a outras especialidades e a outros profissionais, como o psiquiatra, o psicólogo, o assistente social, etc. Nesse aspecto, a abrangência da clínica ensinada no hospital é muito limitada e não favorece a incorporação de outras técnicas de abordagem dos problemas de saúde, não apreensíveis à tecnologia hospitalar.

Com esse tipo de formação, é fácil entender porque os médicos se sentem, em geral, impotentes e desmotivados, trabalhando em um Centro de Saúde.

Retomamos, assim, a discussão inicial deste texto: a especificidade do ensino na Atenção Primária e junto à Comunidade não é dada pelos serviços; a especificidade é dada pelo objetivo do ensino realizado ali, e pode se constituir em elemento dinâmico da reformulação das práticas em cada serviço. O objetivo não é "integrar conhecimentos", "desenvolver habilidades", "complementar a formação hospitalar", "reorientar e redispor o aprendizado das especialidades". O objetivo fundamental é organizar a reflexão sobre o trabalho médico, tendo a clínica como fio condutor. A especificidade do atendimento médico nos
Centros de Saúde aparece, então, como problema em aberto, problema que vai ser enfrentado pela constante experimentação de modos de trabalho médico nesses serviços, apoiados pela pesquisa e pela reavaliação constante do aprendizado.

Nesse sentido, há de ser retomada toda a discussão sobre a relação tecnologia/ciência, de modo a deixar claro para o aluno que o saber cientificamente fundado não se resume àquele que permite a produção e o consumo de equipamentos e medicamentos, e sua utilização. A tecnologia não-material, consubstanciada na consulta médica, na anamnese, exame físico e no raciocínio clínico tem a mesma base científica das tecnologias materiais, e seu desenvolvimento, no espaço do Centro de Saúde, é atribuição da Academia. Desmonta-se, por esse caminho, a visão preconceituosa de que o "comum" é igual ao "simples", e de que o "raro" é "complexo". Essas conjunções não se sustentam no confronto com a realidade do atendimento de primeira linha. $\mathrm{O}$ atendimento médico nos Centros de Saúde, assim como o ensino no Centro de Saúde, não é complementar ao hospitalar. São duas realidades assistenciais distintas que, por força da racionalidade impressa nos projetos de hierarquização da assistência, acabaram por se polarizar de modo funcional à própria reprodução dos modelos assistenciais excedentes: Centro de Saúde = para pobre, caso simples, comuns, desinteressantes, rotina, carência tecnológica; Hospital = acesso universal, casos graves e complexos, estimulantes, interessantes, concentração tecnológica.

O objetivo do ensino no Centro de Saúde é transgredir essa lógica preconceituosa, que não é exclusiva da "matriz flexneriana", mas de todas as matrizes que informam majoritariamente as reformas médicas. Nesse sentido, esse objetivo não se vincula a qualquer matriz em particular, ao mesmo tempo em que pode servir de ponto de apoio às propostas de reforma, inclusive as mais recentes:

1- centrada no estudante;

2- integrada e integradora;

3- baseada em problemas;

4- relevância dos problemas prioritários;

5- avaliação formativa;

6- uso do tempo eletivo;

7- igual ênfase nos conhecimentos, destreza e atitudes;

8- conhecimentos essenciais;

9- capacidade de análise e avaliação crítica;

10- grupos pequenos e docentes facilitadores;

11- formação dos docentes além de sua especialidade. ${ }^{3}$ 


\section{A EXPERIÊNCIA DO DEPARTAMENTO DE PEDIA- TRIA NA INTEGRAÇÃO DO ENSINO NA ATENÇÃO PRIMÁRIA À SAÚDE E NA COMUNIDADE}

O Departamento de Pediatria iniciou sua experiência de ensino em Atenção Primária, no ano de 1971, no Centro de Saúde Escola de Paulínia.

A partir de 1982, após alteração curricular, o Departamento de Pediatria desenvolve atividades de ensino e pesquisa em Centros de Saúde da Rede Básica de Saúde do Município de Campinas. Nesse momento, iniciou-se uma experiência ímpar: atividades docente-assistenciais em Unidades de Saúde "comuns", da própria rede, em um espaço totalmente diferente dos Centros de Saúde Escola. É importante destacar que, embora atuando em unidades da rede, a supervisão dos alunos e residentes é feita apenas por docentes, não se delegando o ensino aos médicos dos serviços.

Em 1995, com a denúncia do convênio Unicamp/ Prefeitura Municipal de Paulínia, por parte desta última, encerraram-se as atividades da Faculdade de Ciências Médicas no Centro de Saúde Escola. A área de Pediatria Social, em processo de reflexão sobre suas experiências de integração com a Rede de Saúde, optou por trabalhar apenas em unidades próprias da rede.

A prática docente-assistencial em Centros de Saúde Escola já é de domínio de várias escolas médicas no país; porisso, neste texto, propomo-nos a relatar a experiência do Departamento de Pediatria em unidades da rede.

Inicialmente atuando com alunos do Internato ( $5^{\circ}$ ano), em estágios de um mês, em que realizam consultas supervisionadas por docentes, as atividades foram ampliadas para alunos do $4^{\circ}$ ano e para a Residência em Pediatria. A orientação do trabalho sempre esteve baseada nas premissas anteriormente colocadas, mesmo que sem a clareza dos objetivos, finalidades e meios com que podemos nos expressar hoje.

Essa experiência gerou dois frutos importantes: 1- trouxe, para dentro do Departamento, a reflexão sobre a relação Pediatria/Criança/Estrutura Social, antes abarcada apenas, (o que não é pouco), pelo aspecto doutrinário da Pediatria e da Puericultura;

2- possibilitou a construção de um modelo clínico de atendimento nos Centros de Saúde, que, por sua vez, favoreceu uma dada concepção de trabalho do médico pediatra para o conjunto da rede de Centros de Saúde, assim como a formulação de um modelo assistencial para o conjunto das necessidades de saúde da criança. Esse modelo não é o modelo pensado pelos docentes, mas o diálogo sempre esteve presente, (às vezes mais tranqüilamente, outras com dificuldades), e, com certeza, serviu para balizar as formulações dos responsáveis pela área da criança da Secretaria Municipal.

Além da atividade de consultas, os internos participam de seminários, relativos às ações dos Centros de Saúde voltadas à criança (Imunizações, Alimentação, Avaliação de Crescimento e de Desenvolvimento NeuroPsicoMotor) e, também, sobre temas clínicos, referentes aos problemas de saúde de maior prevalência e que têm sido relegados pelo ensino hospitalar (Tuberculose, Desnutrição, Anemias Carenciais, Parasitoses, Dificuldades Emocionais, Dores Recorrentes, Dificuldades Escolares, Enurese, etc). A discussão dos casos, com apoio nesta bibliografia e nos seminários, é fundamental para a percepção da existência de um conhecimento e uma modalidade de prática clínica que não tem nada a ver com a abordagem hospitalar. A possibilidade do seguimento desses casos também permite ao aluno checar a eficácia da conduta, estabelecendo ao mesmo tempo uma dinâmica assistencial que se contrapõe, positivamente, ao modelo de pronto-atendimento e queixa-conduta, padrão da rede básica atual.

Para ampliar e aprofundar a percepção da relação do trabalho médico com as necessidades individuais e coletivas de saúde, uma outra atividade foi introduzida: a Vigilância Epidemiológica e Sanitária, compreendendo a fundamentação teórica sobre vigilância à saúde da criança e atividades práticas, de preparo e realização de visita domiciliar. Nas visitas, é feito o agendamento de uma consulta no CS, com o próprio aluno-visitador. $\mathrm{O}$ aluno faz, ainda, um relatório da visita no prontuário da criança, preparando a consulta. Um aspecto importante dessa atividade consiste na construção teórica da própria vigilância à saúde da criança, seja no plano individual ou coletivo; esse campo de conhecimentos ainda carece de uma definição, por ter sido, historicamente, relegado tanto pela Pediatria como pela Saúde Coletiva.

Além disso, com o intuito de relevar os aspectos sócio-culturais e afetivos, presentes na consulta pediátrica, há uma atividade semanal de discussão da relação médico-mãe-criança, que denominamos "Dinâmica da Consulta Pediátrica". É uma atividade coordenada por dois docentes, um pediatra e uma psicóloga especializada em crianças; aqui também é for- 
necida uma bibliografia de apoio, porém seu desenrolar é aberto às questões levantadas pelos alunos. Estabelece-se uma dinâmica de grupo que permita aos alunos refletir sobre esses aspectos, facilitando a aquisição de uma postura médica compreensiva e a elaboração de conflitos que, evidentemente, todo aluno ou médico formado possui, e que, queirendo-se ou não, permeiam a relação médico-paciente.

Essas mesmas atividades são desenvolvidas com os residentes de Pediatria, no primeiro ano, durante o estágio de Pediatria Social, que dura 12 semanas. É lógico que o aprofundamento é maior, pelo tempo disponível e pela experiência clínica de cada um. Para os residentes, é colocada como tarefa a elaboração de uma pesquisa relativa a aspectos que envolvam os assuntos tratados no âmbito do estágio e que vão desde perfis epidemiológicos até a representação médica sobre questões que envolvem a saúde da criança. Essas pesquisas são orientadas por docentes da área de Pediatria Social e apresentadas ao final do estágio; várias já foram encaminhadas para publicação e apresentação em congressos.

Desse modo, pensamos estar ampliando a percepção do aluno de Medicina sobre questões concretas, que não têm como ser tematizadas no âmbito hospitalar de forma conseqüente. Ao mesmo tempo, ao ampliar essa percepção, não o fazemos no sentido de criar perplexidades, mas dando subsídios para o enfrentamento desses problemas presentes na prática clínica, mesmo na especializada. Saímos da denúncia da inadequação do ensino hospitalar para a conformação de uma atividade acadêmica que, ao mesmo tempo em que responde a necessidades postas pelo conjunto dos usuários dos Centros de Saúde, reelabora a prática clínica inserida nessas unidades de serviço, de modo a imprimir nela uma marca científica e tecnológica própria. Ao fazê-lo, buscamos superar, no ensino médico, a eterna clivagem existente entre as disciplinas do social e aquelas das áreas clínicas. Não se trata, portanto, de integração, mas da construção de uma nova prática clínica.

Acreditamos que um dos grandes "buracos negros" da pesquisa médica é exatamente esse, a reflexão sobre o trabalho concreto do médico nos distintos serviços de saúde, vazio que vem sendo preenchido com grande qualidade, mas ainda lentamente, por pesquisadores como Donnangelo ${ }^{4,5}$, Mendes Gonçalves ${ }^{6,7}$ e Schraiber ${ }^{8}$, que ultrapassam a abordagem utilitária do trabalho médico. Acreditamos que a Reforma Sanitária, entendida como projeto de transformação da estrutura de prestação de serviços de saúde, empolgará mais os médicos, em geral, quando puderem enxergar uma possibilidade de crescimento profissional no trabalho realizado no âmbito dos serviços públicos. Nesse sentido, a criação de espaços dedicados ao ensino, à pesquisa e à experimentação da atividade clínica, no âmbito da Rede Básica de Saúde, envolvendo profissionais da rede e estabelecendo para esses profissionais mecanismos de capacitação em serviço, pode contribuir para tirá-los da situação maçante em que se encontram, dando-lhes outros referenciais para o trabalho e a oportunidade de se engajarem na pesquisa e no estudo orientado.

\section{CONCLUSÃO}

A inserção do ensino médico na Rede Básica obedece a uma série de interesses e intenções, contidos implicitamente nos objetivos e finalidades dos estágios. No entanto, esses interesses e ambições devem ser claramente explicitados no âmbito do projeto global de ensino da Faculdade, levando em conta os diferentes marcos conceituais que fundamentam as propostas dos estágios/atividades.

De acordo com esse princípio e buscando desenvolver áreas e instrumentos de ensino e pesquisa ainda não explorados no âmbito dos serviços públicos, o Departamento de Pediatria, através da área de Pediatria Social, vem conseguindo atuar em parceria com a Secretaria Municipal de Saúde de Campinas, há quinze anos. O aspecto relevante do trabalho, no âmbito do ensino médico, é a oportunidade de docentes, alunos e residentes refletirem sobre o trabalho médico nos serviços de primeira linha, na área de assistência à criança, tomando como ponto de apoio a atividade clínica. As questões de saúde são, assim, tematizadas a partir do indivíduo, numa linha de abordagem pouco privilegiada nos programas de ensino integrados à Rede Básica e à Comunidade.

Assumimos, neste aspecto, as considerações de Vaitsman": "A existência de saúde, que é física e mental - está ligada a uma série de condições irredutiveis umas às outras. Um conceito ampliado não poderia então considerar saúde só como resultante das formas de organização social da produção. Pois é produzida dentro de sociedades que, além da produção, possuem certas formas de organização da vida cotidiana, de sociabilidade, da afetividade, de sensualidade, da subjetividade, da 
cultura e do lazer, das relações com o meio ambiente. É antes resultante do conjunto da experiência social, individualizada em cada sentir $e$ vivenciada num corpo que é também, não esqueçamos, biológico. Uma concepção de saúde não reducionista deveria recuperar o significado do in- divíduo em sua singularidade e subjetividade na relação com os outros e com o mundo". (p.171)

Por fim, queremos destacar que a experiência do Departamento de Pediatria da Faculdade de Ciências Médicas da UNICAMP é reprodutível no âmbito das outras disciplinas do ensino médico.

MENDES RT; SILVA PEMR da \& MOYSÉS MAA. Medical apprenticeship in primary health care community services. Medicina, Ribeirão Preto, 29: 420-428, oct./dec. 1996.

ABSTRACT: After retrieving the historical relationship between teaching medicine, medical assistance and research carried out beyond the university ambient, the authors present a concept of education to be used in the Public Health Services.

This concept when compared to the better known and more important Projects for the Reformation of the Teaching of Medicine, provides a basis for the critical review of the aims and objectives of these projects. It also recovers the possibility of widening the vision of medical students, about the health problems that affect children and the specific work performed by these services, through the development of clinical practice at the Health Centers of the Basic Network of the County of Campinas.

Clinical practice conducted at the Health Centers, together with the teaching and research developed there, is based on the fact that good health and sickness are situations felt and experienced by individuals in a society, without excluding knowledge obtained from epidemiology , social sciences and clinical physio-pathalogical-anatomy.

Reflecting on this research, it is possible to see that there are other teaching possibilities that could be introduced in the Basic Network and which haven't been taken into consideration by the Projects for the Reformation of the Teaching of Medicine.

UNITERMS: Primary Health Care. Education, medical. Pediatrics.

\section{REFERÊNCIAS BIBLIOGRÁFICAS}

1 - FLEXNER A. Medical Education in United States and Canadá: a Report to the Carnegie Foundation for the Advancement of Teaching. Bulletin $\mathbf{n}^{\circ}$ 4DB Updike, The Merrymont Press, Boston, 1910.

2 - KOSIK K. Dialética do concreto. Paz e Terra, Rio de Janeiro, 230 p.,1976.

3 - VENTURELLI, I. Inovaciones educacionales em salud: Educacion medica y em ciencias de la salud, 65 p., s.d. (mimeografado).

4 - DONNANGELO MCF. Medicina e sociedade. Pioneira, São Paulo., 1975, $174 \mathrm{p}$.

5 - DONNANGELO MCF. Saúde e sociedade, Duas Cidades. São Paulo, 123 p., 1976.

6 - MENDES GONÇALVES RB. Medicina e História - Raízes sociais do trabalho médico. Tese de Mestrado. Faculdade de Medicina da USP, São Paulo, p. 1240, 1979.

7 - MENDES GONÇALVES RB. Tecnologia e organização social das práticas de saúde: características tecnológicas do processo de trabalho na rede estadual de centros de saúde de São Paulo, Tese de Doutorado. Faculdade de Medicina da USP, São Paulo, p.1-415, 1986.
8 - SCHRAIBER LB. O Médico e Seu Trabalho: Limites da Liberdade. Hucitec, São Paulo, 210 p., 1983.

9 - VAITSMAN J. Saúde, cultura e necessidades. In: FLEURY S. org. Saúde coletiva? Questionando a Onipotência do Social, Relume-Dumará, Rio de Janeiro, 230 p., 1992.

\section{BIBLIOGRAFIA RECOMENDADA}

1 - SCHRAIBER LB. Educação médica e capitalismo, Hucitec/ ABRASCO, Rio de Janeiro, 133 p., 1989.

2 - PAIM JS. Recursos humanos em saúde no Brasil: problemas crônicos e desafios. Faculdade de Saúde Pública/USP, São Paulo. Saúde Temática: Ad Saúde, 80 p., 1994.

3 - CAMPOS GWS. Os médicos e a política de saúde. Hucitec., São Paulo 214 p., 1989.

4 - SCHRAIBER LB. Profession medica: representacion, trabajo y cambio. Educ Med y Salud 25, (1), 1991

Recebido para publicação em 23/10/96

Aprovado para publicação em 11/12/96 